GIS一理論と応用

Theory and Applications of GIS, 1994, Vol. 3, No. 1, pp. 17-24.

道路ネットワーク上における商圈確定法

北村賢之、岡部篤行

\title{
A Method for estimating market areas on a network
}

Masayuki Kitamura and Atsuyuki Okabe

\begin{abstract}
This paper formulates Huff's model on a network, and develops a method for estimating market areas. The method uses an 'exponential distance' , a transformation from a network space to an 'exponential distance space' . By the transformation, the estimation of market areas becomes tractable. Computational methods are also developed.
\end{abstract}

Keywords: ハフモデル、ネットワーク距離空間、指数ネットワーク距離空間

1.はじめに

エリアマーケティングの分野において、最も基本 的な分析は、需要分析、すなわちある店舗にどの程 度の来客があるかを推定する分析であろう。この分 析のために従来用いられてきた代表的なモデルに、 ハフモデル(Huff, 1962)がある。このモデルを用いる と、ある商業施設を選択する確率が一定値以上であ るような圈域(いわゆる商圈)を推定することが可能 になる。

これまでハフモデルは、多くの場合、ユークリッ ド平面上で適用されてきた。モデル適用の初期の段 階では、距離を直楾距離で定義するのが最も容易で あったためと推察される。しかし、距離を直線距離 で定義することは、都市空間内の任意の 2 点間を無 制約に移動できることを仮定しており、都市の実態 には即していない。都市内においては、自由に移動 できる空間は原則的として公道上しかありえないた めである。

この問題を解決するためには、公道上しか移動で

\footnotetext{
北村：テ113 東京都文京区本鄉7-3-1 東京大学工学部 都市工学科 Department of Urban Engineering, University of Tokyo, 7-3-1 Hongo, Bunkyo, Tokyo 113 Tel. 03-3812-2111 ext. 6227
}

きないという制約を加える必要があるが、それは、 都市の道路ネットワークを唯一の移動可能な都市空 間とみなすことによって実現する。このネットワー ク空間においては、任意の 2 点間の距離はネットワ ークに沿った最短距離で定義される。本論文の主旨 は、このネットワーク空間上でハフモデルを適用し、 商圈を確定するというものである。

道路ネットワークを利用するもう一つの理由は、 数理的な理由に基づいている。エークリッド空間に おいてハフモデルを適用し、商圈を求めようとする 従来の方法は、商圈の境界線が解析的に求められな い曲線になるため、対象区域をメッシュに細分し、 商圈をメッシュ単位で求めるか、対象区域内に代表 点をいくつかとり、補間することで商圈を求めるか のいずれかのアプローチを取らざるを得なかった。 しかし、前者にはメッシュのサイズに起因する誤差 が、後者には補間に伴う誤差が不可避に生じ、いず れにせよ数学的な意味における誤差が生じてくるこ とは避けられなかった。しかし、ネットワーク空間 上でハフモデルを適用すれば、商圈の境界は、点の 集合として表され、いかなる場合においても商圈境 界を(解析的な意味においても)䈗密に求めることが 
可能になるのである。

本論文では、ネットワークの特性を生かした商圈 の効率的な確定方法について論じる。第2節では、 ハフモデル式を定義し、 $\alpha$ 商圈、 $\alpha$ 境界の概念を導 入し、都市をネットワーク空間と見ることのメリッ トについて論ずる。第3節では、本論文の骨子であ る、ネットワーク距離空間、および指数ネットワー ク距離空間の概念を導入した上で、ネットワーク上 の $\alpha$ 商圈境界の厳密解の導出と、厳密解を列举する 実用的なアルゴリズムについて論じる。第4節では、 同様の手法によって $\alpha$ 商圈だけでなく、商業施設利 用利便性が一定以上の領域(等効用面)も、効率的に 求めることができることを示す。そして第5節でこ の手法の適用可能性について論じる。

\section{2. ハフモデルと $\alpha$ 商圈}

\section{1 ハフモデル}

今、均質な平面上に商業施設が $n_{s}$ 個立地している 状況を考えよう。便宜上どの 2 つの商業施設も同一 地点にはなく、また各商業施設は、魅力度 $A_{j}$ という 属性値以外は同質で互いに差がないとする。このと き、平面上の地点iに立地している需要者は、魅力度 がより高く、またより自分の近くに位置する商業施 設を利用しようとするであろう。利用可能な情報が、 商業施設の魅力度 $\left(A_{j}\right)$ とiから各商業施設 $j$ までの距離 $\left(d_{i j}\right)$ だけであるとするなら、iにいる需要者が商業施 設 $j$ 利用する確率は、 $A_{j}$ に比例し、 $d_{i j}$ に反比例する ような関数形で表すことができる。代表的な関数形 としては、

$$
A_{j} \exp \left(-\lambda d_{i j}\right)
$$

が挙げられる。この関数形を仮定した上で、 $n_{s}$ 個あ

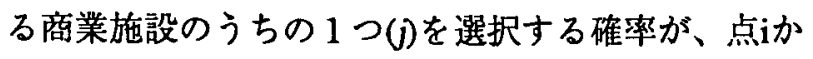
ら全ての商業施設へのこの関数值の総和に対する関 数値jの比率に比例すると考えるのがハフモデルの 基本的な考え方である。

ハフモデルは関数形として式(1)を用いると次のよう に書ける。

$$
P(i, j)=\frac{A_{j} \exp \left(-\lambda d_{i j}\right)}{\sum_{k=1}^{n_{s}} A_{k} \exp \left(-\lambda d_{i k}\right)}
$$

ここで、

$P(i, j)$ : 地点iの需要者の商業施設 $j$ の選択確率

i : 実空間上の任意の位置

j : 商業施設

$d_{i j}: i j$ 間の距離

$j \quad$ ：商業施設 $\mathrm{j}$ 魅力度

$\lambda$ : 係数(減哀度係数 $)^{1}$ )

\section{$2.2 \alpha$ 商圈}

式(2)によってある地点ににおける商業施設jの選択 確率を計算することが可能であるが、逆に、この式 を利用して、商業施設 $j$ 選択する確率が一定值 $\alpha$

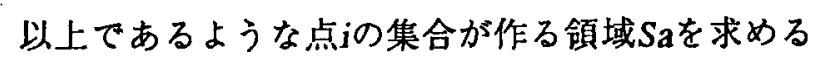
ことを考えよう。数式で表すと、

$$
S_{\alpha}=\left\{i \mid \frac{A_{j} \exp \left(-\lambda d_{i j}\right)}{\sum_{k=1}^{n_{s}} A_{k} \exp \left(-\lambda d_{i k}\right)} \geq \alpha\right\}
$$

となる。ここで領域 $S a を ~ \alpha$ 商圈と名付ける。

実際に $\alpha$ 商圈を求めるには、その境界線だけを求 めればよい。 $\alpha$ 商圈の境界線を $\alpha$ 境界と呼ふことに すると、明らかに $\alpha$ 商圈は $\alpha$ 境界の内側(商業施設 $j$ を含む側)の領域である。 $\alpha$ 境界は式(3)の不等号を 等号で置き換えた式、

$$
(1-\alpha) A_{j} \exp \left(-\lambda d_{i j}\right)-\alpha \sum_{k \neq j} A_{k} \exp \left(-\lambda d_{i k}\right)(4)
$$

を満たす。式(4)を $\alpha$ 境界条件式と呼ぶ。

ここで、空間をユークリッド平面上とすると、 $\mathrm{n}_{\mathrm{s}}>2$ 2のケースでは、式(4)を解いてiの軌跡を解析的 に求めることができないという問題が生ずる。すなわ ち、ユークリッド平面上では一般に $\alpha$ 境界を陽に求 めることは難しいのである。

そこで次に、ネットワーク空間の場合を考えよう。 
すなわち、都市空間を一様な平面としてでなく、道 路ネットワークによって形作られる離散空間と解釈 するのである。一般にユークリッド平面上では、 $\alpha$ 境界は一般の曲線となり、解析的に求めることが難 しいが、ネットワーク上では、 $\alpha$ 境界は点の集合と

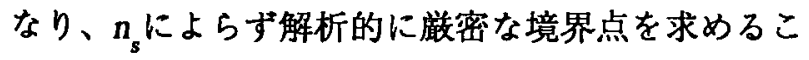
とができるのである。また、都市をネットワーク空 間とみなすことは、前述したような理由から、実際 の意味においても現実に即しているといえる。都市 内の全ての建築物は、必ず接道しているので、現実 の商業施設を全てネットワーク上に写像することは 原理的にはさほど困難ではない。

\section{3. ネットワーク上での $\alpha$ 商圈境界点の導出}

\section{1 ネットワーク距離空間}

本節では実際にネットワーク上での $\alpha$ 境界点を求 める手続きについて論じる。

式(4)より、 $\alpha$ 境界の条件は、ある地点门商業施 設との間の距離 $d_{i j}$ のみによって定まり、iや商業施設 のx,y座標などは $\alpha$ 境界点確定に直接必要ないこと がかかる。そこで、各商業施設からの距離を座標軸 に取った、新たな座標系2)を設定し、その座標系上 にネットワークを写像してみることにしよう。この 新たな座標系によって定義される空間をネットワー ク距離空間と呼ふことにすると、 $\alpha$ 境界点の確定を ネットワーク距離空間上で行うことにより、問題を 簡略化することができる。

実際に、ネットワークをネットワーク距離空間に写 像するには、以下の操作を行えばよい。

1) 商業施設弲ら最短距離木を張る。このとき、 ネットワークリンクのうち最短距離木に含まれな いリンク上には、両端点を経由したjまでの $2 つ$ の距離が等しくなるような点(衝突点と称する。 図1の点a,b,c,d,e)が必ず存在する。

2) 衝突点を新たなネットワークノードとして挿 入し、ネットワークリンクを切断する。衝突点の 挿入によって分けられた後のネットワークリンク を特に細分リンクと呼ぶ。細分リンク中では、各
商業施設への距離の変化が単調であることに注意され たい。

3）以上の操作を全ての商業施設について繰り返 した後、ネットワークノードをネットワーク距離 空間に写像する。ネットワーク距離空間において もネットワークノードを結ぶ位相的関係は変化し ないので、ここまででネットワーク距離空間上の ネットワークが得られる。

ここで、上記の操作に伴って生成される細分リン クの本数を求めてみよう。もし、細分リンクの本数 がもとのリンク本数に対して指数的に増加するよう では、上記の操作は理論的には可能でも実際的には 不可能となってしまう。

もとのネットワークのリンク本数をL、ノード数 をN、商業施設数をsとする。1つの商業施設から最 短距離木を張るときに生成される衝突点は、もしネ

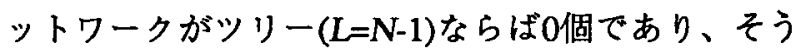
でなければッリーと比べて圥長なリンクの本数 (L$(N-1))$ 個分しか高々増加しない。これがs回繰り返さ れるので、最終的な細分リンク本数は、

$$
L+s\{L-(N-1)\}=(1+s) L-s(N-1)
$$

となり、一般にL〉>Sであるから細分リンク数は高々 もとのリンク数と同じオーダーにおさまることがわ かる。

図 1、図 2 にネットワークをネットワーク距離空 間に写像した例を示す。

ネットワーク距離空間に写像されたネットワーク の性質については四茂野(1991)によって導出された 次の定理が重要である。

定理： ns次元ネットワーク距離空間上では、ネッ トワークリンクの方向ベクトルは、

$$
\left((-1)^{\delta_{1}},(-1)^{\delta_{2}}, \cdots,(-1)^{\delta_{n_{s}}}\right) \quad \delta_{k}=1 \text { or } 2
$$

に限定されている。従って、リンクの取りうる方向 の数は、互いに一次独立な方向ベクトルの本数に等 しく、 $2^{n_{\mathrm{s}}-1}$ 種類しかない。

ネットワーク空間内で、ある点から微小距離移動 
した場合を考えると、移動により、各商業施設への 距離は離れるか近づくかのいずれかであり(变化し ないことはあり得ない)、しかもその変化量の絶対 值は等しいという事実が、定理の直観的な証明を与 える。また、仮に実空間上のネットワークが直線分 によって棈成されていなくても、ネットワーク距離 空間上では必ず直楾分で表されるという点も特筆さ れる。

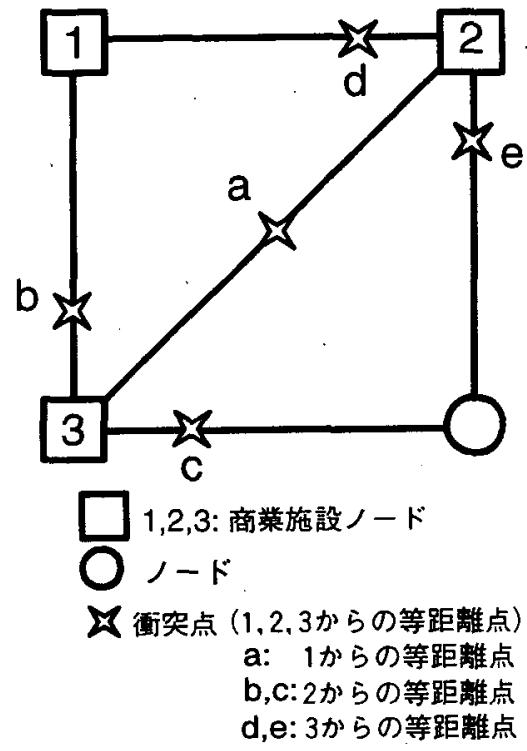

図 1 、実空間上のネットワーク

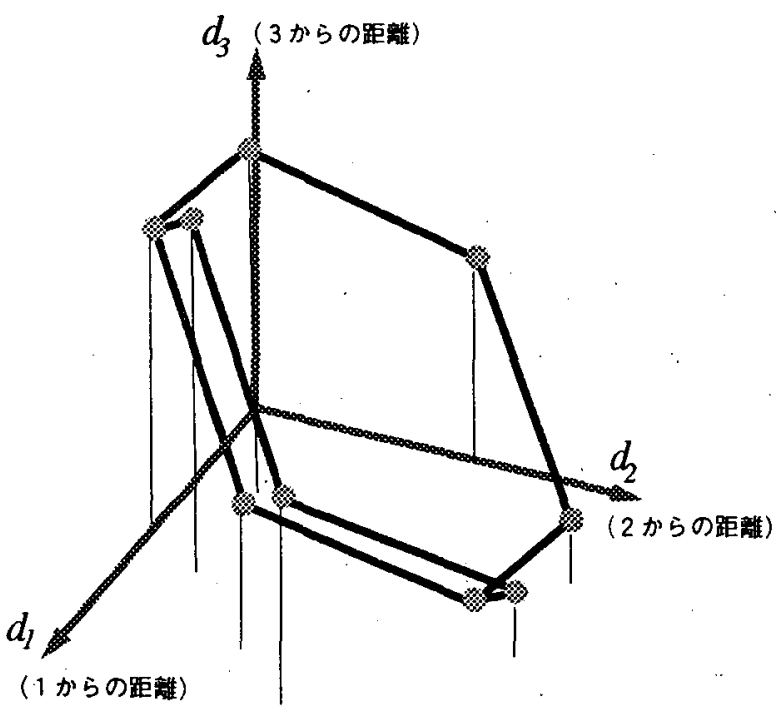

図 2 ネットワーク距離空間上のネットワーク
3.2 指数ネットワーク距離空間 $n_{s}>2$ 2のースでは、ネットワーク距離空間において も式(4)を解析的に解くことは困難である。そこで、 ネットワーク距離空間に、さらに次の変換を施した 座標系を考える。

$$
\exp \left(-\lambda d_{i j}\right) \rightarrow X_{j}
$$

この新しい空間を指数ネットワーク距離空間と呼ふ。 指数ネットワーク距離空間上では、式(4)は次のよう になる。

$$
(1-\alpha) A_{j} X_{j}-\alpha \sum_{k \neq j} A_{k} X_{k}=0
$$

この式の形からも明らかに、指数ネットワーク距 離空間上において、 $\alpha$ 境界条件式はns次元空間上の 原点を通る超平面によって表現される。この超平面 を $a$ 境界面と呼ぶことにしよう。 $\alpha$ 境界面は、

$$
0 \leq d_{i j} \leq \infty \text { より } 0 \leq X_{j} \leq 1 。
$$

原点を通り、

$$
\begin{gathered}
A=\left(-\alpha A_{1}, \cdots,-\alpha A_{j-1},(1-\alpha) A_{j},\right. \\
\left.-\alpha A_{j+1}, \cdots,-\alpha A_{n_{s}}\right)
\end{gathered}
$$

を法線ベクトルとする平面の $0 \leq X_{j} \leq 1$ の部分。 という性質を持っている。

一方、指数ネットワーク距離空間において、ネット ワークはどのように表されるのであろうか。ネット ワーク距離空間上の細分リンクをLとし、Lの両端点 を $\mathbf{v}_{s}=\left(d_{s 1}, \cdots, d_{s n_{s}}\right), \mathbf{v}_{e}=\left(d_{e 1}, \cdots, d_{e n_{s}}\right)$ とすると、 L上の動点pは、 $t(0<\mathrm{t}<1)$ をパラメータとしたベクト ル表示で、

$$
\mathbf{p}=(1-t) \mathbf{v}_{s}+t \mathbf{v}_{e}=\mathbf{v}_{s}+t\left(\mathbf{v}_{e}-\mathbf{v}_{s}\right)
$$

と書け、定理より、リンクLの方向ベクトルが、

$$
\begin{aligned}
& \mathbf{v}_{e}-\mathbf{v}_{s}=l_{0}\left((-1)^{\delta_{1}}, \cdots(-1)^{\delta_{n_{2}}}\right)=l_{0} \mathbf{n} \\
& \left(l_{0}=\frac{\left\|\mathbf{v}_{e}-\mathbf{v}_{s}\right\|}{\sqrt{n_{s}}}\right) .
\end{aligned}
$$


(12)

と書けることから、式(9)は

$$
p=v_{\mathrm{s}}+\mathrm{t}_{6} n
$$

となる。

次に、この細分リンクLを、指数ネットワーク距 離空間上に変換することを考える。リンクL上の動 点pを指数変換すると、

$$
\begin{aligned}
& \exp (-\lambda \mathbf{p})=\exp \left\{-\lambda\left(\mathbf{v}_{s}+t_{0} \mathbf{n}\right)\right\} \\
& =\left(\exp \left\{-\lambda\left(d_{s 1}+t l_{0}(-1)^{\delta_{1}}\right)\right\}, \cdots, \exp \left\{-\lambda\left(d_{s n_{0}}+t l_{0}(-1)^{\delta_{s}}\right)\right\}\right) \\
& =\left(X_{1}, \cdots X_{n_{1}}\right)
\end{aligned}
$$

となる。

リンクLの指数ネットワーク距離空間上における表 現は、式(12)からパラメータtを消去することで得ら れる。式(12)より、

$$
\left\{\begin{array}{c}
X_{1}=\exp \left\{-\lambda\left(d_{s 1}+t l_{0}(-1)^{\delta_{1}}\right)\right\} \\
\vdots \\
X_{n_{s}}=\exp \left\{-\lambda\left(d_{s n_{s}}+t l_{0}(-1)^{\delta_{n_{s}}}\right)\right\}
\end{array}\right.
$$

辺々自然対数を取ることにより、

$$
\begin{aligned}
& t=\frac{-\ln X_{1}-\lambda d_{s 1}}{\lambda l_{0}(-1)^{\delta_{1}}}=\cdots=\frac{-\ln X_{n_{s}}-\lambda d_{s n_{s}}}{\lambda l_{0}(-1)^{\delta_{s_{s}}}} \\
& -\lambda l_{0} t=(-1)^{\delta_{1}}\left(\ln X_{1}+\lambda d_{s 1}\right) \\
& =\cdots=(-1)^{\delta_{n_{s}}}\left(\ln X_{n_{s}}+\lambda d_{s n_{s}}\right)
\end{aligned}
$$

辺々指数を取ると、

$$
E_{1} X_{1}^{(-1)^{\delta_{1}}}=\cdots=E_{n_{s}} X_{n_{s}}^{(-1)^{\delta_{n_{s}}}}=T
$$

ただし、

$$
\begin{aligned}
& E_{i}=\exp \left((-1)^{\delta_{i}} \lambda d_{s i}\right) \\
& T=\exp \left(-\lambda l_{0} t\right) \\
& \left(0 \leq t \leq 1, \exp \left(-\lambda l_{0}\right) \leq T \leq 1\right)
\end{aligned}
$$

となって、細分リンクの指数ネットワーク距離空間 上における表現式が得られた。

式(15)の概形を直観的に理解するために、 $n_{s}=3$, , のケースについて考えてみよう。このとき、式(15) は、係数を無視すれば、

$$
X_{1}=\frac{1}{X_{2}}=X_{3}
$$

となる(係数 $E_{i}$ は必ず正になり概形には影響を与え ない。これは、 $X_{1}$ と $X_{3}$ が比例し、 $X_{1}$ と $X_{2}, X_{3}$ と $X_{2}$ が反比例の関係にあることを意味しており、この図 形は、平面 $X_{1}=X_{3}$ 上にあって直線 $X_{1}=X_{3}=0\left(X_{2}\right.$ 軸 $)$ と 直線 $X_{1}=X_{3}, X_{2}=0$ に漸近する双曲線(の一部)を表して いる。

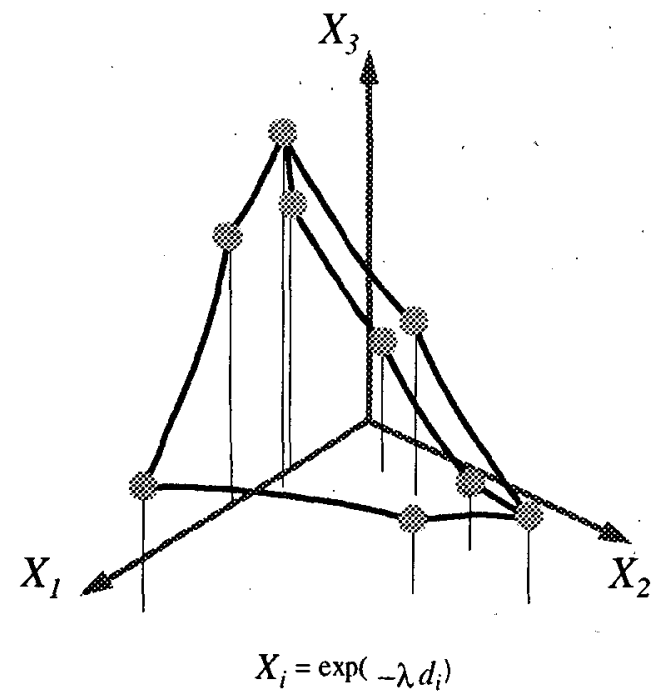

図 3 指数ネットワーク距離空間上のネットワーク

このように式(15)は、 $\delta_{1}=\delta_{2}=\cdots=\delta_{n_{s}}$ のとき $n_{s}$ 次元空間内の「直線分」となり、それ以外の時に は原点に対して凸な双曲線分を表すことがわかる。 指数ネットワーク距離空間におけるネットワークリ

\section{ンクの性質}

$\delta_{1}=\delta_{2}=\cdots=\delta_{n_{s}}$ のとき

原点を通り方向ベクトルが、 


$$
\left\{\begin{array}{l}
\left(E_{1}, E_{2}, \cdots, E_{n_{s}}\right) \quad\left(\delta_{i}=1\right) \\
\left(\frac{1}{E_{1}}, \frac{1}{E_{2}}, \cdots, \frac{1}{E_{n_{s}}}\right) \quad\left(\delta_{i}=2\right)
\end{array}\right.
$$

であるような直線の一部分。

\section{それ以外のとき}

原点に対して凸な双曲線の一部分。

\section{$3.3 \alpha$ 境界点導出}

前項までの議論で、指数ネットワーク距離空間と いう新しい空間を定義すると、 $\alpha$ 境界条件式が超平 面、ネットワークリンク(細分リンク)が直線分、も しくは双曲線分で表されることがわかった。ネット ワーク上における $\alpha$ 境界点は、二つの図形の交点で 表される。すなわち、指数ネットワーク距離空間上 においては、 $\alpha$ 境界点確定問題は超平面と直線分も しくは双曲線分の交点を列挙する問題に帰着する。 数学的には、これはまさに式(8)と式(15)を連立させ てパラメータtを求める問題である。前項で述べ た、 $\alpha$ 境界面が原点を通る超平面であるという性質 から、1 本の細分リンクと $\alpha$ 境界面の交点の個数は 高々1個であることが予想される。

式(15)は、

$$
X_{k}=\left(\frac{T}{E_{k}}\right)^{(-1)^{\lambda_{k}}}=\exp \left(-\lambda d_{s k}\right) T^{(-1)^{s_{k}}}
$$

と変形できる。これを式(8)に代入すると、

$$
\begin{aligned}
& (1-\alpha) A_{j} \exp \left(-\lambda d_{s j}\right) T^{(-1)^{\delta_{j}}} \\
& -\alpha \sum_{k \neq j} A_{k} \exp \left(-\lambda d_{s k}\right) T^{(-1)^{\delta_{k}}}=0
\end{aligned}
$$

が得られ、ここで、

$$
\begin{cases}B_{k}=-\alpha A_{k} \exp \left(-\lambda d_{s k}\right) & (k \neq j) \\ B_{k}=(1-\alpha) A_{k} \exp \left(-\lambda d_{s k}\right) & (k \neq j)\end{cases}
$$

を導入すると、式(17)は、

$$
\sum_{i}^{n_{B}} B_{i} T^{(-1)^{\delta_{k}}}=0
$$

となる。

ここで、式(19)は、各項が $\delta_{k}$ の值 (1または2)によ って、 $\mathrm{B}_{\mathrm{k}} / \mathrm{T} 、 ま た は \mathrm{~B}_{\mathrm{k}} \mathrm{T}$ と書けるという点に着目す ると、次のように整理できる。

$$
B_{\text {sum } 1} / T+B_{\text {sum } 2} T=0
$$

ただし、

$$
B_{s u m 1}=\sum_{\left\{k \mid \delta_{k}=1\right\}} B_{k}, \quad B_{s u m 2}=\sum_{\left\{k \mid \delta_{k}=2\right\}} B_{k}
$$

両辺にてを掛けて整理することにより、

$$
T^{2}=-\frac{B_{\text {sum } 1}}{B_{\text {sum } 2}} \quad \therefore T=\left(-\frac{B_{\text {sum } 1}}{B_{\text {sum } 2}}\right)^{\frac{1}{2}}
$$

となる( $\exp \left(-\lambda u_{0}\right) \leq T \leq 1$ より)。

$T=\exp \left(-\lambda l_{0} t\right) よ り$ 、求めるパラメー夕tは、

$$
t=\frac{1}{2 \lambda l_{0}} \ln \left(-\frac{B_{\text {sum1 }}}{B_{\text {sum2 }}}\right)
$$

という形で得られる。ここで、もし、た0またはっ1 ならば $\alpha$ 境界点はそのリンク上には存在せず、なら、 この值は細分リンク上の $\alpha$ 境界点を示すべクトル パラメータとなる。

\section{4 効率的なアルゴリズム}

以上の操作をネットワークを構成する全てのリン クに適用すれば、 $\alpha$ 境界点を全て求めることができ る。しかし、単純に全てのリンクに適用するよりも 効率の良いアルゴリズムが存在する。 式(4)の左辺を $\mathrm{f}(\mathrm{a}, \mathrm{i}, \mathrm{j})$ とおく。すなわち、

$$
f(\alpha, i, j)=(1-\alpha) A_{j} \exp \left(-\lambda d_{i j}\right)-\alpha \sum_{k \neq j} A_{k} \exp \left(-\lambda d_{i k}\right)
$$

fは、商圈を調べる商業施設 、確率 $\alpha$ が与えられ

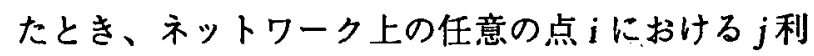
用確率に関する正の増加関数であり、 $\mathrm{f}(\mathrm{a}, \mathrm{i}, \mathrm{j})>0$ な ら $\mathrm{i}$ の $\mathrm{j}$ 利用確率は $\alpha$ 以上、 $f(a, \mathrm{i}, j)=0$ ならば $\mathrm{i}$ は $\alpha$ 一境界点である。すなわち、 $\mathrm{f}=0$ は $\alpha$ 一境界面その ものに対応している。 
細分リンク上でトは明らかに連続であるから、ある ネットワークリンクの両端ノードのfの值を求め、

もし符号が逆ならばそのネットワークリンク中には 必ず $\alpha$ 境界点が含まれる。

このことを利用すると、 $\alpha$ 境界点を全て列挙する ためには、fの值が正(または負)であるノードから出 るリンクだけをチェックすればよいことがわかる。 具体的には、例えば、下のようにノードjから幅優 先探索(腰塚他,1993)を用いることによって、効率的 なアルゴリズムが実現できる。

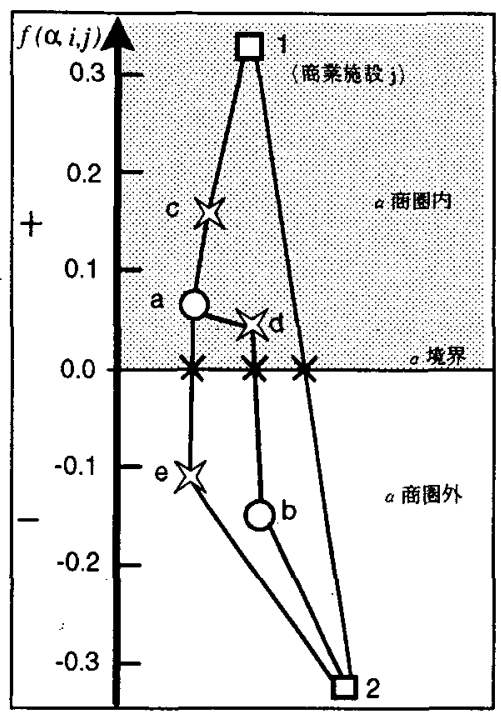

図 $4 \mathrm{f}(\mathrm{a}, \mathrm{i}, \mathrm{j})$ とネットワーク

ノードjからの幅優先探索による $\alpha$ 境界列挙アル ゴリズム゙)

1)次ノード候補セットWを準備する。Wには最初ノ ードうをれておく。

2)以下をWが空になるまで繰り返す。

2-1) W中で $f(a, i, j)$ が最大のノードをノードaとす る。

2-2）aと接続するノードを結ぶリンク上に $\alpha$ 境界 がないかどうかを前述の方法で調べる。

2-3) a と接続するノードのうち、 $f(a, i, j)>0$ ののを 全てWに入れる。( $\left(\mathrm{a}, i_{2},\right)<0$ のードは $\alpha$ 境界の 外側)

このアルゴリズムは、值が正であるノード( $\alpha$ 商 圏に含まれるノード)の数が少ないほど効率が高く

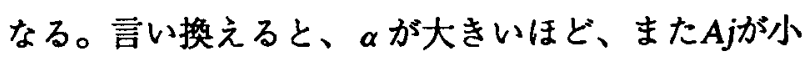
さいほど効率が高くなる。

\section{4、等効用面の確定}

\section{1 等効用面}

本節では、ネットワークと商業施設の配置が所与 であるとき、ネットワーク上の地点ににおける商業 施設の利用利便性について考えてみる。 式(2)の右辺の分母、すなわ方、

$$
u_{i}=\sum_{k=1}^{n_{s}} A_{k} \exp \left(-\lambda d_{i k}\right)
$$

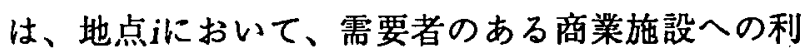
用度を全ての商業施設について合計した值である。 一般に、この值(u)が大きければ大きいほど、地点 $i$ は商業施設を利用しやすい、言い換えると商業施設 利便性の高い地点であると考えることができる。そ こで、 $u_{i}$ を地点iの利便性(あるいは効用)と呼ふこと にすると、 $u_{i}$ が等しい点の集合、すなわち、等利便 性面(等効用面)は、次式、

$$
\sum_{j=1}^{n_{s}} A_{j} \exp \left(-\lambda d_{i j}\right)=u
$$

u: 効用レベル(定数)

を満たすうの集合となる。これは指数ネットワーク 距離空間上では、

$$
\sum_{j=1}^{n_{s}} A_{j} X_{j}=u
$$

と、前節の $\alpha$ 境界面同様超平面として表現される。 4.2 ネットワーク上における等効用点の確定

ネットワーク上における等効用点は、指数ネット ワーク距離空間上において、式(15)で表される細分 リンクと、式(23)で表される等効用面との交点とし て表現される。この交点を求める操作は、境界面が 原点を通らない超平面になる(の場合)という点を除 けば、前節の $\alpha$ 境界点の確定となんら変わるところ はない。 
式(15)より、

$$
X_{j}=\left(\frac{T}{E_{j}}\right)^{(-1)^{\delta_{j}}}=\exp \left(-\lambda d_{i j}\right) T^{(-1)^{\alpha_{j}}}
$$

となるので、これらを式(23)に代入することにより、

$$
\sum_{j=1}^{n_{s}} B_{j} T^{(-1)^{\delta_{j}}}=u \quad\left(B_{j}=A_{j} \exp \left(-\lambda d_{i j}\right)\right)
$$

を得る。等効用点を求めるには、式(24)を、Tにつ いて、 $\exp \left(-\lambda l_{0}\right) \leq T \leq 1$ の範囲で解けばよい。 djの值によって、Bjを別々に集計する。すなわち、

$$
B_{s u m 1}=\sum_{\left\{k \mid \delta_{k}=1\right\}} B_{k}, \quad B_{s u m 2}=\sum_{\left\{k \mid \delta_{k}=2\right\}} B_{k}
$$

すると、式(24)は、

$$
B_{\text {sum } 2} T+B_{\text {sum } 1} \frac{1}{T}=u
$$

となり、両辺に $T$ を掛けると、

$$
B_{\text {sum } 2} T^{2}-u T+B_{\text {sum } 1}=0
$$

となる。このとき、 $u^{2}-4 B_{\text {sum } 1} B_{\text {sum } 2} \geq 0$ を満たし ていれば、これを解いて、交点の $T$ 値、

$$
T=\frac{u \pm \sqrt{u^{2}-4 B_{\text {sum } 1} B_{\text {sum } 2}}}{2 B_{\text {sum } 2}}
$$

を得る。ただし、Tがの範围内になければその解は 不適当であり、適当な解が1つもなければその細分 リンク上には等効用点は存在しないことになる。 式(26)より、対応する $t$ 值は、

$$
t=-\frac{1}{\lambda l_{0}} \ln T_{\alpha}=-\frac{1}{\lambda l_{0}} \ln \left(\frac{u \pm \sqrt{u^{2}-4 B_{\text {sum } 1} B_{\text {sum } 2}}}{2 B_{\text {sum } 2}}\right)
$$

となり、実空間上に扔ける等効用点も、これらの $t$ 值から求めることができる。

ある細分リンク上に等効用点が存在する条件は、

$$
\begin{aligned}
& u^{2}-4 B_{\text {sum } 1} B_{\text {sum } 2} \geq 0 \text { かつ、 } \\
& \exp \left(-\lambda_{0}\right) \leq T \leq 1 \text { なる }
\end{aligned}
$$

$$
T=\frac{u \pm \sqrt{u^{2}-4 B_{\text {sum } 1} B_{\text {sum } 2}}}{2 B_{\text {sum } 2}} \text { が存在すること。 }
$$

1 本の細分リンク上に存在する等効用点の個数は 高々 2 個であることは自明である。

\section{5.まとめ}

本論文では、ハフモデルを用いた商圏確定問題 が、ネットワークの利用と指数ネットワーク距離空 間への変換によって、きわめて容易に解けることを 示した。この手法は、単に商圈の確定のみならず、 4で示したようなある種の施設の等効用面の確定(施 設は商業施設だけに限られない)など、様々な用途 に拡張できる可能性を持っており、エリアマーケテ イングや都市計画分野において特に有用であろうと 思われる。

\section{謝辞}

なお、本論文をまとめるにあたり、長岡造形大学の 四茂野英彦氏より貴重な示唆を得た。紙面を借 りてお礼申し上げます。

\section{参考文献}

Huff , David L. "Determination of Intra-Urban Retail Trade Areas". Los Angeles: Real Estate Research Program, Univ. of California, 1962 四茂野 秀彦 (1991)「空間の最近隣距離変換」未発表 腰场 武志他 (1993) 「計算幾何学と地理情報処理第 2 版」共立出版

注)

1)本論文で取り上げるモデルでは、入は常に一定値 をとることにする。そのため、潜上現象 ( 2 商 業施設間の商圈境界が相手の背後側にも生じる 現象)が発生する恐れはなく、求められるネッ トワーク上の商圈は常に連結なグラフになる。

2) 商業施設がns個あるケースでは、距離空間はns次 元空間となる。

3)このアルゴリズムを実空間上で見ると、商業施設 jから始まってネットワーク上を幅優先探索で 探索し、 $\alpha$ 一商圈内にある全てのノードを調べ 終えた時点で探索を終了している。 